\title{
Prevalence of the metabolic syndrome in Pudong New Area of Shanghai using three proposed definitions among Chinese adults
}

\author{
Wang-hong Xu11, Xiao-nan Ruan², Xiao-jin Fu³, Qiu-li Zhu², Hong Zhang², Yun Bai³, Hong-yan Wu22, Yi Zhou², Hua Qiu², \\ Qiao Sun², Qing-wu Jiang1', Li-ming Yang², Jian-jun Gu*3 and Gen-ming Zhao*1
}

\begin{abstract}
Background: The prevalence of metabolic syndrome (MS) has been increasing in China in recent years. The aim of this study is to estimate and compare the prevalence of MS among Chinese adults in Shanghai, one of the most economic developed areas in China, using definitions proposed by World Health Organization (WHO), National Cholesterol Education Program Adult Treatment Panel (modified ATP III) and International Diabetes Federation (IDF).

Methods: This cross-sectional study included 5,584 adults at age 20-79 randomly selected from Pudong New Area of Shanghai, China, through a three-stage sampling. All participants were interviewed in-person between April and July of 2008 to collect information on demographic and lifestyle characteristics. At the interview, anthropometry and blood pressure were measured and bio-specimens were collected.

Results: The prevalence estimates for the MS increased with age for each definition in men and women, but the estimates varied greatly between the definitions and by sex. The prevalence of the MS was higher in men (20.2\%) than in women (18.7\%) using WHO definition but this sex difference was reversed when using the modified ATP III (28.4\% for men vs. $35.1 \%$ for women) and the IDF (15.9\% for men vs. $26.7 \%$ for women) criteria. The most common metabolic disorder in this population was dyslipidaemia, regardless of the definition used. Substantial agreement, estimated using the kappa statistic, was found between the modified ATP III and IDF definition, whereas the lowest agreement was observed between the WHO and ATP III criteria.

Conclusions: The MS is highly prevalent among Chinese adults in Pudong New Area of Shanghai and the most prevalent component was dyslipidemia. These findings underscore the importance of prevention and control efforts for the MS in this area and the need for a unified predictive definition for the syndrome for use by clinical practitioners and public health agencies.
\end{abstract}

\section{Background}

The metabolic syndrome (MS) is a cluster of the most dangerous risk factors for type 2 diabetes mellitus and cardiovascular disease (CVD), including abdominal obesity, hypertension, hyperglycemia and dyslipidemia. When these metabolic abnormalities occur in the same

*Correspondence: gujj2228@yahoo.com.cn, gmzhao@shmu.edu.cn

1 Department of Epidemiology, School of Public Health, Fudan University;

Key Laboratory of Public Health Safety, Ministry of Education (Fudan University),

138 Yi Xue Yuan Road, Shanghai 200032, China

3 Health Bureau of Shanghai Pudong New Area, 820 Cheng Shan Road,

Shanghai 200125, China

Full list of author information is available at the end of the article individual they confer an additional cardiovascular risk above and beyond the contribution of the individual components $[1,2]$. It is estimated that the risk from the MS for major cardiovascular events is approximately twice as high as for those with the syndrome compared to those without it, and the risk for type 2 diabetes is around fivefold greater for those with the MS [2-4].

The MS is becoming epidemic around the world and the prevalence of the MS has been estimated to be more than 20\%. The high prevalence of the MS has been reported not only in developed countries [5-7] but also in developing regions [8,9], including China [10-13]. China has experienced a remarkable economic expansion in the

(c) 2010 Xu et al; licensee BioMed Central Ltd. This is an Open Access article distributed under the terms of the Creative Commons AttriB. Wed Central bution License (http://creativecommons.org/licenses/by/2.0), which permits unrestricted use, distribution, and reproduction in any medium, provided the original work is properly cited. 
past three decades, and Pudong New Area of Shanghai is one of the most economically active areas in the country. This area of Shanghai has experienced a rapid nutrition transition characterized by an increasingly sedentary lifestyle and substantial dietary changes (e.g., increasingly energy-density) [14], as well as a dramatic aging of the population [15]. These changes are likely to have contributed to a high prevalence of the MS and increased risk for type 2 diabetes, CVD and premature death. In order to evaluate and predict the burden of CVD and other chronic diseases in this area, population-based estimates of the prevalence of the MS are needed.

So far, however, there has been no definition of the MS accepted universally. Currently, several definitions of the MS have been proposed for use, and each definition has a slightly different emphasis. While the one proposed by World Health Organization takes insulin resistance as a required component [16], the modified ATP III criteria treat the five components equally [17]. The IDF definition, on the other hand, puts an emphasis on central obesity [18]. Due to the lack of internationally agreed-upon criteria to define the condition, the prevalence of the MS has varied widely across different studies. Comparisons between the prevalence of the MS using these definitions may help better understand the characteristics of metabolic disorder among Chinese adults and facilitate interventions to prevent the MS and subsequent development of CVD.

In this study, we estimated and compared the prevalence of the MS by applying the three definitions of the condition in a representative sample of the residents in Pudong New Area of Shanghai, China.

\section{Methods}

\section{Participants of the study}

This cross-sectional study was conducted from April to July of 2008 among permanent residents of Pudong New Area of Shanghai, China, who had lived in the area for 5 years or more. A total of 6,387 eligible adults (20-79 yrs) were randomly selected from the area using a three-stage sampling design. Firstly, all 30 streets in this area were classified into three groups (each with 10 streets) according to the residents' average social economic status [14] and 12 streets (4 from each group) were randomly selected. Then, a total of 34 communities, which hold about 71,000 eligible residents, were randomly selected from the 783 communities in the selected streets. The expected number of participants in each community was calculated as $9.0 \%$ of its eligible population. Finally, a house number was randomly selected in each community as the first family interviewed. All eligible subjects in the selected families were recruited. Pregnant women and physically or mentally disabled persons were excluded from the survey. Of the 6,387 eligible adults contacted, 5,584 were interviewed and donated blood and urine samples, yielding a response rate of $87.4 \%$. Of these participants, 2,477 were male and 3,107 were female, and 804 non-participants (12.6\%) declined to be interviewed for miscellaneous reasons. The study was approved by Fudan University Institutional Review Board (IRB00002408, FWA00002399).

\section{Data collection}

After obtaining written consent, a structured in-person interview was conducted by trained interviewers to elicit information about demographic factors, diagnosis of hypertension, diabetes and hyperlipidemia, tobacco and alcohol use, physical activity, and family history of hypertension and diabetes. At the interview, each participant was also measured for his/her blood pressure, body weight, standing height, and circumference of the waist and hip by trained staff. Blood pressure (BP) was measured on the right arm in the sitting position using standard mercury sphygmomanometer after at least 5 minutes of rest. The first and fifth Korotkoff sounds were recorded. Body height was measured to the nearest 0.1 $\mathrm{cm}$ by using a stadiometer. Girth measurements, recorded to the nearest $0.1 \mathrm{~cm}$, were taken with a cloth tape. Waist circumference (WC) was measured at the midline between the lower border of the ribs and the iliac crest (usually at a level of $2.5 \mathrm{~cm}$ above the umbilicus) in the horizontal plane after a normal expiration. Hip circumference was defined as the maximum girth reading between waist and thigh. Body weight was measured with electronic scales to the nearest $0.1 \mathrm{~kg}$. Two measurements were taken, with tolerances of $<5 \mathrm{mmHg}$ for blood pressure, $<1 \mathrm{~cm}$ for height and circumference, and $<1 \mathrm{~kg}$ for weight. A third measurement was taken if the difference between the first two exceeded the tolerance. The mean of the replicates was used in the following analyses. Body mass index (BMI: weight in kilograms divided by height in meters squared, $\mathrm{kg} / \mathrm{m}^{2}$ ) and waist-to-hip circumference ratio (WHR) were calculated using the direct measurements.

\section{Laboratory measurements}

All participants were asked to provide $10 \mathrm{ml}$ fasting blood and $50 \mathrm{ml}$ morning void urine for biochemical analysis in Shanghai Second People's Hospital. An automatic Biochemical Analyzer (HITACHI 7170A, Hitachi, Ltd, Tokyo, Japan) was used to measure the levels of fasting plasma glucose (FPG), triglycerides (TG), high-density lipoprotein cholesterol (HDL-C), low-density lipoprotein cholesterol (LDL-C) and total cholesterol (TC), as well as urinary concentrations of creatinine and albumin by using enzymology or immunoradiometry methods. Qual- 
ity control of the assays was assessed internally and externally. The interassay coefficient of variation was $<1.5 \%$ for FPG,$<1.6 \%$ for $\mathrm{TG},<3.0 \%$ for $\mathrm{TC},<2.9 \%$ for HDL-C, $<1.6 \%$ for LDL-C, $<7.0 \%$ for urinary album, and $<2.1 \%$ for urinary creatinine.

\section{Definitions of the metabolic syndrome}

The WHO criteria [16] for the MS required the presence of diabetes mellitus or impaired fasting plasma glucose (FPG $\geq 5.6 \mathrm{mmol} / \mathrm{L}$ ) and at least two of the following components: 1) diagnosed with hypertension or blood pressure: $\geq 140 / 90 \mathrm{mmHg}$; 2) dyslipidemia: TG $\geq 1.695$ $\mathrm{mmol} / \mathrm{L}$ or HDL-C $\leq 0.9 \mathrm{mmol} / \mathrm{L}$ (male), $\leq 1.0 \mathrm{mmol} / \mathrm{L}$ (female); 3) central obesity: WHR > 0.90 (male); > 0.85 (female), or BMI $\geq 30 \mathrm{~kg} / \mathrm{m}^{2}$; or 4) microalbuminuria: urinary albumin to creatinine ratio (ACR) $\geq 30 \mathrm{mg} / \mathrm{g}$.

The modified ATP III definition of the MS [17] required the presence of at least 3 or more of the following 5 components: 1 ) elevated WC: $\geq 90 \mathrm{~cm}$ (male), $\geq 80$ cm (female); 2) elevated TG: > $150 \mathrm{mg} / \mathrm{dL}$ (1.695 mmol/ L); 3) reduced HDL-C: < $1.036 \mathrm{mmol} / \mathrm{L}$ (male), < 1.295 $\mathrm{mmol} / \mathrm{L}$ (female); 4) hypertension or elevated BP: $\geq 130 /$ $85 \mathrm{mmHg}$; or 5) diabetes or elevated FPG: $\geq 5.6 \mathrm{mmol} / \mathrm{L}$.

The 2006 International Diabetes Federation (IDF) definition classified a person with the MS in the same way as ATP III, but required the presence of central adiposity (elevated WC) as an essential component [18].

\section{Statistical analysis}

Statistical analysis was conducted using SAS (version 8.1; SAS Institute, Cary, NC). Chi-square and student $t$ tests were used to compare the difference between categorical and numeric variables. Age-standardized prevalence of the MS was calculated based on the age distribution of the standard world population. Logistic regression models were fit to evaluate the association of individual metabolic abnormalities with the MS. In addition, kappa statistics were calculated to determine the level of agreement between the three MS definitions. P values $<0.05$ were considered statistically significant.

\section{Results \\ Measured metabolic characteristics of the study population}

Table 1 presents the measured metabolic characteristics in our population. Compared to women, men had a significantly higher WC, WHR, BMI, higher systolic and diastolic BP and higher levels of FPG and TG. Men also had lower levels of HDL-C and ACR than women. The differences between men and women in prevalence of elevated BMI or WC were not significant, but men had a higher prevalence of elevated BP, FPG and TG, while women had a higher prevalence of low HDL-C and elevated ACR (Table 1).

\section{Sex and age-specific prevalence of the MS in the study population}

The prevalence of the MS was observed to increase with increasing age in both sexes by either one of the three definitions. It is of note that the age-specific prevalence was higher in men than in women in early adulthood (before age of 65 according to WHO definition and at age of 40 using ATP III and IDF criteria) but appeared lower during elderly period (Table 2). The MS was more common in men $(20.2 \%)$ than in women $(18.7 \%)$ using WHO definition but was otherwise according to modified ATP III (28.4\% for men vs. 35.1 for women) and IDF (15.9\% for men vs. $26.7 \%$ for women) criteria.

\section{Prevalence of individual metabolic abnormalities in the study population}

The prevalence of individual metabolic abnormalities is presented in Table 3. According to WHO criteria, dyslipidemia, i.e. elevated TG or reduced HDL-C, was the most common metabolic abnormality in both men $(56.9 \%)$ and women $(47.8 \%)$, followed by central obesity, elevated FPG, raised BP and presence of microalbuminuria. Among the five metabolic abnormalities defined by modified ATP III or IDF criteria, elevated TG also ranked first in both sexes (59.2\% for men and $49.7 \%$ for women), followed by elevated BP (49.0\% for men and $44.8 \%$ for women), elevated FPG (36.7\% for men and 32.2\%), increased WC (22.1\% for men and 38.5 for women) and reduced HDL-C (11.1\% for men and $19.3 \%$ for women). In this population, the present of 1 or 2 metabolic abnormalities was most common in both men and women.

\section{Prevalence of the MS among subjects with a certain metabolic abnormality}

Figure 1 shows the prevalence of MS estimated by each definition in all participants and among subjects with a specific metabolic abnormality. The prevalence of the MS was $40.0 \%$ for the men and $34.5 \%$ for the women with elevated WC using WHO definition, but the prevalence estimated was substantially greater when using the modified ATP III (71.6\%) and IDF criteria (69.3\%). Among the subjects with high BP, only $32.5 \%$ of the men and $34.1 \%$ of the women had the MS using the WHO definition whereas $50.0 \%$ of the men and $63.2 \%$ of the women were classified as such according to the modified ATP III definition. Difference in the prevalence of MS was also observed among subjects having other individual metabolic abnormalities.

\section{Association of individual metabolic abnormalities with the} MS

We also examined the association of the individual metabolic abnormalities with the MS. Subjects with any one metabolic disorder were more likely to be diagnosed with the MS by modified ATP III definition (Table 4). Microal- 
Table 1: Measured metabolic characteristics of the selected Chinese adults in Pudong New Area of Shanghai, China

\begin{tabular}{|c|c|c|c|}
\hline Characteristics & Male $(\mathrm{N}=2477)$ & Female ( $\mathrm{N}=3107$ ) & P value \\
\hline \multicolumn{4}{|l|}{$W C$} \\
\hline Mean \pm SD & $83.9 \pm 9.2$ & $78.3 \pm 9.4$ & $<0.0001$ \\
\hline$\geq 90 \mathrm{~cm}$ for male & 22.1 & & \\
\hline$\geq 80 \mathrm{~cm}$ for female & & 38.5 & $<0.0001$ \\
\hline \multicolumn{4}{|l|}{$B M I$} \\
\hline Mean \pm SD & $24.1 \pm 3.3$ & $23.8 \pm 3.5$ & $<0.0001$ \\
\hline$\geq 30 \mathrm{~kg} / \mathrm{m}^{2}$ & 4.5 & 5.3 & 0.16 \\
\hline \multicolumn{4}{|l|}{$W H R$} \\
\hline Mean \pm SD & $0.88 \pm 0.06$ & $0.83 \pm 0.07$ & $<0.0001$ \\
\hline$>0.90$ for male & 38.3 & & \\
\hline$>0.85$ for female & & 37.9 & 0.93 \\
\hline \multicolumn{4}{|l|}{ Systolic BP } \\
\hline Mean \pm SD & $128 \pm 16.1$ & $126 \pm 19.6$ & $<0.0001$ \\
\hline$\geq 130 \mathrm{mmHg}$ & 40.3 & 37.5 & 0.03 \\
\hline \multicolumn{4}{|l|}{ Diastolic BP } \\
\hline Mean \pm SD & $81 \pm 9.5$ & $80 \pm 10.1$ & $<0.0001$ \\
\hline$\geq 85 \mathrm{mmHg}$ & 27.0 & 24.6 & 0.05 \\
\hline \multicolumn{4}{|l|}{ FPG } \\
\hline Mean \pm SD & $5.8 \pm 1.9$ & $5.7 \pm 1.6$ & 0.0003 \\
\hline$>5.6 \mathrm{mmol} / \mathrm{l}$ & 35.9 & 31.4 & 0.0006 \\
\hline \multicolumn{4}{|l|}{$H D L-C$} \\
\hline Mean \pm SD & $1.34 \pm 0.26$ & $1.48 \pm 0.27$ & $<0.0001$ \\
\hline$<1.036 \mathrm{mmol} / \mathrm{l}$ for male & 11.1 & & \\
\hline$<1.295 \mathrm{mmol} / \mathrm{l}$ for female & & 25.8 & $<0.0001$ \\
\hline \multicolumn{4}{|l|}{$T G$} \\
\hline Mean \pm SD & $2.4 \pm 2.1$ & $2.1 \pm 1.7$ & 0.0001 \\
\hline$>1.695 \mathrm{mmol} / \mathrm{l}$ & 56.5 & 47.0 & $<0.0001$ \\
\hline \multicolumn{4}{|l|}{ Urinary $A C R$} \\
\hline Mean \pm SD & $2.0 \pm 9.2$ & $2.8 \pm 11.1$ & $<0.0001$ \\
\hline$\geq 30 \mathrm{mg} / \mathrm{g}$ & 0.8 & 1.6 & 0.0035 \\
\hline
\end{tabular}

$\mathrm{P}$ value for $t$-test (continuous variables) or $\mathrm{X}^{2}$ test (categorical variables).

buminuria, one component of the WHO criteria, was strongly associated with the condition in both sexes, but was not significantly related to the MS in men using the definitions of the ATP III or IDF. Interestingly, regardless of the definition used, subjects with elevated TG were most likely to be diagnosed with the MS, with odds ratios (OR) being 7.6, 15.9 and 5.1 for men and 7.3, 16.5 and 7.7 for women under WHO, ATPIII and IDF definition, respectively, after adjusting for age, BMI, alcohol consumption, cigarette smoking and exercise.

\section{Agreement between the three MS definitions}

Figure 2 shows the overall prevalence of the MS by WHO, modified ATP III and IDF criteria. Nine percent of men and $13.3 \%$ of women were consistently classified as hav- ing the MS by each definition and $68.6 \%$ of men and $64.1 \%$ of women were classified as being free from the MS consistently. The level of agreement between each two definitions was modest, with kappa value ranging from 0.382 to 0.806 (Table 5). Agreement between modified ATP III and IDF criteria was substantial with a kappa of 0.647 for men and 0.806 for women. All subjects classified with the MS by the IDF definition were also classified this way by the ATP III criteria. The lowest level of agreement was between the WHO and IDF definitions in both men $(\kappa=0.382)$ and women $(\kappa=0.469)$.

\section{Discussion}

In this representative sample of adults whose age and sex distribution was similar to that in Pudong New Area of 
Table 2: Sex and age-specific prevalence of the MS according to WHO, modified ATP III and IDF definition among selected Chinese adults in Pudong New Area of Shanghai, China

\begin{tabular}{|c|c|c|c|c|c|c|c|}
\hline & \multirow[t]{2}{*}{ No. of Subjects } & \multicolumn{2}{|c|}{ WHO criteria } & \multicolumn{2}{|c|}{ ATP III criteria } & \multicolumn{2}{|c|}{ IDF criteria } \\
\hline & & No. of MS & $\%$ & No. of MS & $\%$ & No. of MS & $\%$ \\
\hline \multicolumn{8}{|l|}{ Male } \\
\hline & 2477 & 498 & $20.2(15.3)$ & 696 & $28.4(22.7)$ & 391 & $15.9(13.8)$ \\
\hline $20-$ & 141 & 3 & 2.1 & 10 & 7.1 & 9 & 6.4 \\
\hline $25-$ & 124 & 6 & 4.9 & 17 & 14.1 & 14 & 11.6 \\
\hline $30-$ & 134 & 8 & 6.1 & 16 & 12.2 & 12 & 9.2 \\
\hline $35-$ & 142 & 22 & 15.8 & 26 & 18.7 & 17 & 12.2 \\
\hline $40-$ & 204 & 35 & 17.2 & 54 & 26.7 & 34 & 16.8 \\
\hline $45-$ & 314 & 55 & 17.5 & 74 & 23.7 & 38 & 12.2 \\
\hline $50-$ & 309 & 76 & 19.6 & 114 & 29.5 & 61 & 15.8 \\
\hline $55-$ & 348 & 85 & 24.6 & 117 & 33.9 & 61 & 17.7 \\
\hline $60-$ & 258 & 80 & 31.3 & 103 & 40.2 & 51 & 19.9 \\
\hline $65-$ & 162 & 51 & 31.7 & 68 & 42.5 & 38 & 23.8 \\
\hline $70-$ & 173 & 44 & 25.4 & 62 & 35.8 & 34 & 19.7 \\
\hline $75-$ & 88 & 33 & 37.5 & 35 & 40.2 & 22 & 25.3 \\
\hline \multicolumn{8}{|c|}{ Female } \\
\hline & 3107 & 575 & $18.7(12.3)$ & 1078 & $35.1(25.0)$ & 821 & 26.7(19.2) \\
\hline $20-$ & 159 & 0 & 0 & 3 & 1.9 & 3 & 1.9 \\
\hline $25-$ & 176 & 3 & 1.8 & 15 & 8.8 & 14 & 8.2 \\
\hline 30- & 156 & 3 & 1.9 & 13 & 8.4 & 10 & 6.5 \\
\hline $35-$ & 186 & 8 & 4.4 & 33 & 17.9 & 28 & 15.2 \\
\hline 40- & 274 & 20 & 7.4 & 48 & 17.8 & 34 & 12.6 \\
\hline $45-$ & 395 & 59 & 15.0 & 113 & 28.8 & 83 & 21.1 \\
\hline $50-$ & 551 & 98 & 17.9 & 205 & 37.6 & 149 & 27.3 \\
\hline 55- & 468 & 123 & 26.5 & 210 & 45.2 & 172 & 37.0 \\
\hline 60- & 265 & 80 & 30.2 & 147 & 55.5 & 110 & 41.5 \\
\hline 65- & 189 & 59 & 31.9 & 96 & 52.5 & 71 & 38.8 \\
\hline 70- & 188 & 75 & 39.9 & 130 & 69.5 & 99 & 52.9 \\
\hline 75- & 100 & 47 & 47.5 & 65 & 65.7 & 48 & 48.5 \\
\hline
\end{tabular}

In parentheses was the age-standardized prevalence of the MS according to age distribution of the world population.

Shanghai, China [19], we found that the MS was highly prevalent. Using the modified criteria of ATP III for the MS the prevalence was $28.4 \%$ for men and $35.1 \%$ for women. The overall and age-specific prevalence of the MS in this population were much higher than the general levels of Chinese adults in 1992 and 2000-01 [20,21], and were similar to those in other economically developed areas in China $[11,13]$. In fact, the prevalence of the MS was comparable to those in developed countries $[5,22]$.

Consistent with the results from studies in other populations [5,13,22], the prevalence of the MS increased with age in both sexes in our study. We observed a wide dis- crepancy between the crude and age-standardized prevalence of the MS, indicating that the increasing proportion of older adults in the population has contributed much to the overall prevalence of the MS in this area. The number of adults at age 60+ years in Shanghai reached 3.0 million in 2008 , and they account for more than 20 percent of all residents in the city [23]. Interestingly, in early adulthood the age-specific prevalence was higher in men than in women but this pattern was reversed among older adults. The age-specific prevalence pattern we observed was consistent with that in a Japanese population [24], but differed from several other previous studies, in which a 
Table 3: Prevalence of individual metabolic abnormalities among selected Chinese adults in Pudong New Area of Shanghai, China

\begin{tabular}{|c|c|c|c|c|c|c|}
\hline \multirow[t]{2}{*}{ Metabolic abnormalities } & \multicolumn{2}{|c|}{ Male (2477) } & \multicolumn{2}{|c|}{ Female (3107) } & \multicolumn{2}{|c|}{ Total (5583) } \\
\hline & Number & $\%$ & Number & $\%$ & Number & $\%$ \\
\hline \multicolumn{7}{|l|}{ By WHO criteria } \\
\hline Impaired FPG or diabetes & 903 & 36.7 & 992 & 32.2 & 1895 & 34.2 \\
\hline Central obesity & 973 & 39.3 & 1224 & 39.4 & 2197 & 39.3 \\
\hline Elevated BP or hypertension & 778 & 31.4 & 927 & 29.8 & 1705 & 30.5 \\
\hline Microalbuminuria & 19 & 0.8 & 51 & 1.6 & 70 & 1.3 \\
\hline Hyperlipidemia & 1409 & 56.9 & 1485 & 47.8 & 2894 & 51.8 \\
\hline \multicolumn{7}{|l|}{ No. of metabolic abnormalities } \\
\hline 0 & 483 & 19.6 & 859 & 27.9 & 1342 & 24.2 \\
\hline 1 & 682 & 27.7 & 791 & 25.7 & 1473 & 26.6 \\
\hline 2 & 675 & 27.4 & 696 & 22.6 & 1371 & 24.8 \\
\hline 3 & 455 & 18.5 & 495 & 16.1 & 950 & 18.2 \\
\hline 4 & 161 & 6.5 & 226 & 7.3 & 387 & 7.0 \\
\hline 5 & 4 & 0.2 & 13 & 0.4 & 17 & 0.3 \\
\hline \multicolumn{7}{|l|}{ By modified ATP III or IDF criteria } \\
\hline Increased WC & 548 & 22.1 & 1196 & 38.5 & 1744 & 31.2 \\
\hline Elevated BP or hypertension & 1213 & 49.0 & 1393 & 44.8 & 2606 & 46.7 \\
\hline Reduced HDL-C or use drug & 272 & 11.1 & 795 & 25.8 & 1067 & 19.3 \\
\hline Elevated TG or use drug & 1455 & 59.2 & 1532 & 49.7 & 2987 & 54.0 \\
\hline Impaired FPG or diabetes & 903 & 36.7 & 992 & 32.2 & 1895 & 34.2 \\
\hline \multicolumn{7}{|l|}{ No. of metabolic abnormalities } \\
\hline 0 & 418 & 17.0 & 667 & 21.7 & 1085 & 19.6 \\
\hline 1 & 663 & 27.0 & 677 & 22.0 & 1340 & 24.2 \\
\hline 2 & 676 & 27.6 & 652 & 21.2 & 1328 & 24.0 \\
\hline 3 & 460 & 18.8 & 557 & 18.1 & 1017 & 18.4 \\
\hline 4 & 206 & 8.4 & 385 & 12.5 & 591 & 10.7 \\
\hline 5 & 30 & 1.2 & 136 & 4.4 & 168 & 3.0 \\
\hline
\end{tabular}

higher age-specific prevalence of the MS was consistently observed for women $[5,10,11]$. The explanation for this finding is not immediately clear, and the pattern varied by the definition employed. It is possible that the men in Shanghai were at a higher risk of the MS than women, and thus had a higher mortality from CVD and diabetes in later adulthood. In addition, selection biases and chance cannot be excluded. Notably, the cross-over point of the sex specific prevalence estimates by age was much later in life when the WHO definition was used (about age 65), compared to the modified ATP III or IDF criteria (about age 40). This may explain the higher overall prevalence of the MS in men using WHO but the higher preva- lence estimates in women according to modified ATP III and IDF criteria.

Another significant finding in this study is that dyslipidemia, particularly hypertriglyceridemia, is the most common metabolic disorder in our population. This finding is much different from those of a national estimate from all of China [10], even after taking age differences and the MS definitions used in the two studies into account. The differences in MS components may be due to differences in behavioral risk factors (i.e. diet or lifestyle) rather than genetic susceptibility. The rapid "nutrition transition" in Shanghai, characterized by a more sedentary lifestyle and an energy-dense higher fat diet may, at least in part, account for the higher prevalence of 

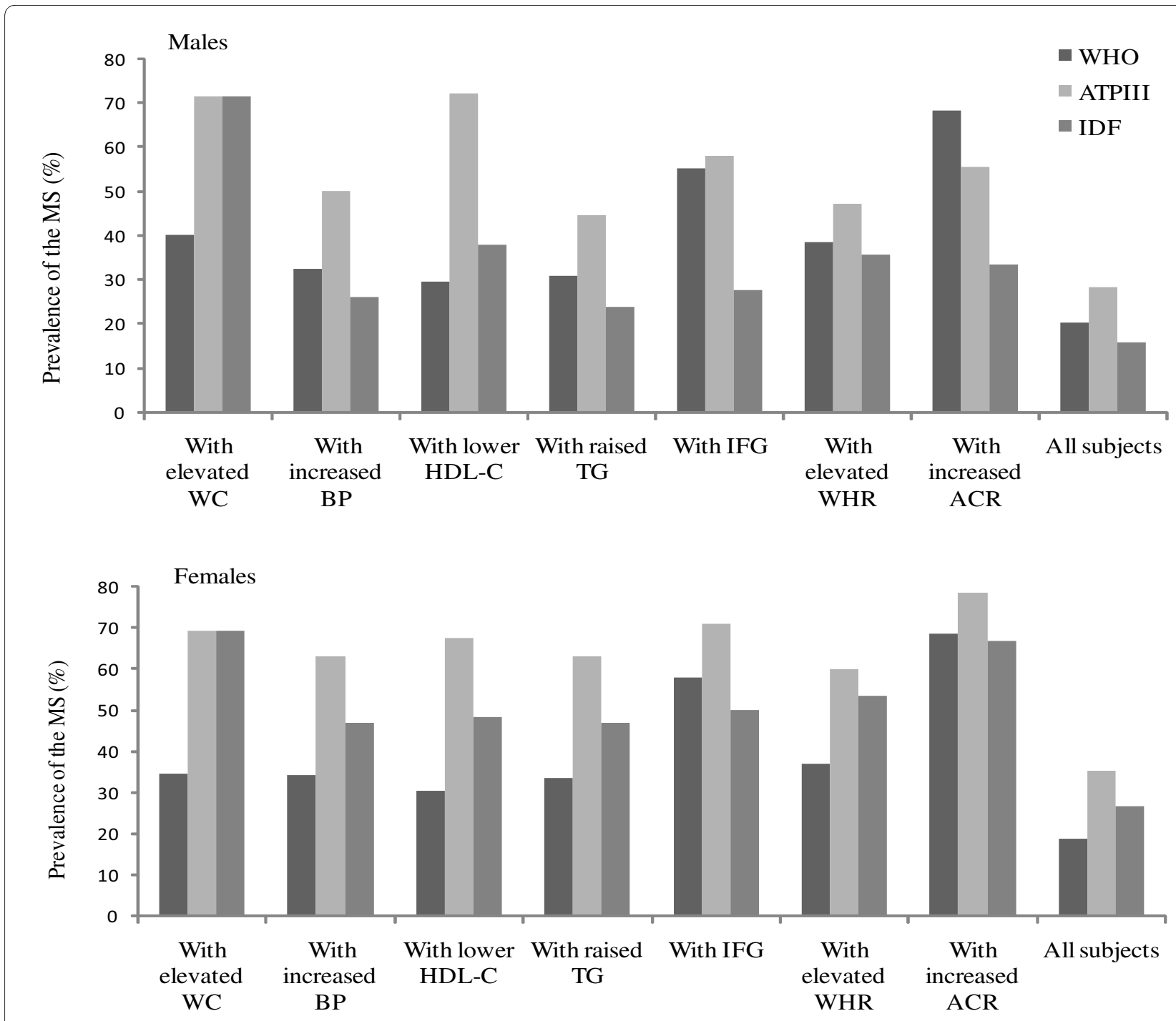

Figure 1 Prevalence of the MS according to WHO, modified ATP III and IDF criteria in all participants and the subjects with each individual metabolic abnormality.

hyperlipidemia in our population. This element of the "nutrition transition" is a central contributor of hyperlipidemia [25] and may function as initiation factor for the MS [26].

Importantly, the distinct characteristic of the metabolic disorder in this population may indicate predictive value of the MS for the risk of CVD and other chronic diseases in the area. The definitions of the MS, either proposed by WHO, ATP III or IDF, similarly focus on obesity, hypertension, hyperglycaemia and dyslipidemia. The MS is usually identified by the presence of at least 3 of 5 metabolic abnormalities. It is thus plausible that the characteristics of the MS vary across populations. For example, blacks in the US are more likely than the whites to have the clustering of obesity, hypertension and diabetes but less likely to have either elevated TG or low HDL-C lev- els, leading to a lower prevalence of the MS but higher rates of diabetes and CVD in the blacks than in the whites [27]. If it is true that dyslipidemia is less important in predicting the diabetes and CVD than other metabolic disorders, as suggested by Sumner et al's [27], the fact that dyslipidemia is the most common metabolic abnormality in our population may indicate and account for the comparable prevalence of the MS but a lower incidence of diabetes and CVD in Chinese adults than in their western counterparts.

The level of agreement we observed among the three definitions was modest and not surprisingly the prevalence of the MS was quite different according to each individual definition employed. This finding is consistent with previous studies conducted in Chinese adults $[13,21]$, and other populations [6,7,28-30]. Although 
Table 4: Association of individual metabolic abnormalities with the MS among selected Chinese adults in Pudong New Area of Shanghai, China

\begin{tabular}{|c|c|c|c|c|c|c|}
\hline \multirow[t]{2}{*}{ Metabolic abnormalities } & \multicolumn{2}{|c|}{ MS by WHO } & \multicolumn{2}{|c|}{ MS by ATP III } & \multicolumn{2}{|c|}{ MS by IDF } \\
\hline & No/Yes & OR(95\%Cl) & No/Yes & OR(95\%CI) & No/Yes & OR(95\%Cl) \\
\hline \multicolumn{7}{|l|}{ Male } \\
\hline \multicolumn{7}{|l|}{ Impaired FPG or diabetes } \\
\hline No & $1557 / 0$ & -- & $1379 / 176$ & 1.0 & $1413 / 142$ & 1.0 \\
\hline Yes & $405 / 498$ & -- & $377 / 521$ & $9.6(7.8-11.9)$ & $648 / 250$ & $3.5(2.8-4.4)$ \\
\hline \multicolumn{7}{|l|}{ Central obesity (WC > $90 \mathrm{~cm}$ ) } \\
\hline No & $1632 / 279$ & 1.0 & $1602 / 305$ & 1.0 & $1907 / 0$ & -- \\
\hline Yes & $329 / 219$ & $3.9(3.1-4.8)$ & $154 / 392$ & $14.9(11.8-18.9)$ & $154 / 392$ & -- \\
\hline \multicolumn{7}{|c|}{ Hypertension or elevated BP (sbp $\geq 130$ or dbp $\geq 85$ mmHg) } \\
\hline No & $1143 / 107$ & 1.0 & $1151 / 96$ & 1.0 & $1170 / 77$ & 1.0 \\
\hline Yes & $819 / 391$ & $4.1(3.2-5.2)$ & $605 / 601$ & $10.7(8.4-13.7)$ & $891 / 315$ & $5.1(3.9-6.7)$ \\
\hline \multicolumn{7}{|l|}{ Microalbuminuria } \\
\hline No & $1956 / 485$ & 1.0 & $1748 / 687$ & 1.0 & $2049 / 386$ & 1.0 \\
\hline Yes & $6 / 13$ & $6.8(2.5-18.7)$ & $8 / 10$ & $2.4(0.9-6.1)$ & $12 / 6$ & $2.1(0.8-5.8)$ \\
\hline \multicolumn{7}{|l|}{ Reduced HDL-C or use druga } \\
\hline No & $1770 / 416$ & 1.0 & $1681 / 502$ & 1.0 & $1893 / 290$ & 1.0 \\
\hline Yes & $192 / 80$ & $1.5(1.1-2.0)$ & $75 / 195$ & $9.9(7.2-13.8)$ & $168 / 102$ & $3.2(2.3-4.6)$ \\
\hline \multicolumn{7}{|l|}{ Elevated TG or use druga } \\
\hline No & $950 / 50$ & 1.0 & $950 / 49$ & 1.0 & $953 / 46$ & 1.0 \\
\hline Yes & $1009 / 446$ & $7.6(5.5-10.4)$ & $806 / 648$ & $15.9(11.3-22.2)$ & $1108 / 346$ & $5.1(3.5-7.4)$ \\
\hline \multicolumn{7}{|c|}{ Dyslipidemia (reduced HDL-C or elevated TG)a } \\
\hline No & $1007 / 60$ & 1.0 & $986 / 76$ & 1.0 & $1001 / 61$ & 1.0 \\
\hline Yes & $955 / 438$ & $7.4(5.5-10.0)$ & $770 / 621$ & 10.9(8.2-14.6) & $1060 / 331$ & $4.2(3.0-5.8)$ \\
\hline \multicolumn{7}{|l|}{ Female } \\
\hline \multicolumn{7}{|l|}{ Impaired FPG or diabetes } \\
\hline No & $2088 / 0$ & -- & $1706 / 380$ & 1.0 & $1757 / 329$ & 1.0 \\
\hline Yes & $417 / 575$ & -- & $288 / 700$ & $8.4(7.0-10.1)$ & $495 / 493$ & $3.9(3.3-4.7)$ \\
\hline \multicolumn{7}{|l|}{ Central obesity (WC > $85 \mathrm{~cm}$ ) } \\
\hline No & $1427 / 166$ & 1.0 & $1631 / 258$ & 1.0 & $1889 / 0$ & -- \\
\hline Yes & $778 / 409$ & $4.0(3.3-4.9)$ & $363 / 822$ & $12.0(10.0-14.5)$ & $363 / 822$ & -- \\
\hline \multicolumn{7}{|c|}{ Hypertension or elevated BP ( $\mathrm{sbp} \geq 130$ or dbp $\geq 85 \mathrm{mmHg}$ ) } \\
\hline No & $1590 / 103$ & 1.0 & $1484 / 205$ & 1.0 & $1515 / 174$ & 1.0 \\
\hline Yes & $915 / 472$ & $4.9(3.8-6.2)$ & $510 / 875$ & $8.3(6.8-10.0)$ & $737 / 648$ & $5.3(4.3-6.5)$ \\
\hline \multicolumn{7}{|l|}{ Microalbuminuria } \\
\hline No & $2489 / 540$ & 1.0 & $1983 / 1040$ & 1.0 & $2235 / 788$ & 1.0 \\
\hline Yes & $16 / 35$ & $7.8(4.0-15.3)$ & $11 / 40$ & $5.3(2.5-11.2)$ & $17 / 34$ & $4.1(2.2-7.8)$ \\
\hline \multicolumn{7}{|l|}{ Reduced HDL-C or use druga } \\
\hline No & $1951 / 333$ & 1.0 & $1738 / 543$ & 1.0 & $1841 / 440$ & 1.0 \\
\hline Yes & $553 / 241$ & $2.3(1.8-2.8)$ & $256 / 537$ & $10.4(8.2-13.1)$ & $411 / 382$ & $4.0(3.2-5.0)$ \\
\hline
\end{tabular}


Table 4: Association of individual metabolic abnormalities with the MS among selected Chinese adults in Pudong New Area of Shanghai, China (Continued)

\begin{tabular}{|c|c|c|c|c|c|c|}
\hline \multicolumn{7}{|c|}{ Elevated TG or use druga } \\
\hline No & $1485 / 62$ & 1.0 & $1432 / 115$ & 1.0 & $1440 / 107$ & 1.0 \\
\hline Yes & $1017 / 511$ & 7.3(5.4-9.7) & $562 / 965$ & $16.5(12.9-21.2)$ & $812 / 715$ & $7.7(6.0-9.9)$ \\
\hline \multicolumn{7}{|c|}{ Dyslipidemia (reduced HDL-C or elevated TG)a } \\
\hline No & $1547 / 73$ & 1.0 & $1456 / 161$ & 1.0 & $1475 / 142$ & 1.0 \\
\hline Yes & $958 / 502$ & $7.1(5.4-9.4)$ & $538 / 919$ & $12.1(9.7-15.2)$ & $777 / 680$ & $5.9(4.7-7.5)$ \\
\hline
\end{tabular}

OR: Adjusted for age as a continuous variable.

a additionally adjusted for BMI (as a continuous variable), cigarette smoking (Never/Ever), alcohol consumption (Never/Ever) and exercise (Never/ever).

$68.6 \%$ of the men and $64.1 \%$ of the women were consistently classified as being free of MS by all 3 definitions, only $9.0 \%$ of men and $13.3 \%$ of women were consistently classified with the MS by all three criteria. More than $20 \%$ of the participants were classified differently using the three definitions. In addition, the prevalence of the MS varied greatly among the subjects with specific individual metabolic abnormalities depending on the definition employed. This reflects that the three definitions have their own respective emphasis. The WHO definition directly assigns greatest value to insulin resistance which is usually indicated by impaired fasting glucose. In contrast, the modified ATP III and IDF definitions do not employ insulin resistance as a required component based on the assumption that the other four components of the MS are linked to insulin resistance. However, significant proportions of those with the four individual components in our sample did not evidence of have insulin resistance as indicted by the criteria employed. For example, there is evidence suggesting no strong link between hypertension and insulin resistance [31]. The phenomenon may explain the discrepancy in the prevalence of the MS in the same population estimated by three definitions. A single worldwide definition of the MS would be desirable to make comparisons between different populations easier and for clinical, epidemiologic and surveillance purposes. There is a need for existing cohort studies in Asia to explore the best and most predictive definition of the MS and its components.

An important limitation of the present study is the cross-sectional design. This fact limited our ability to examine the most predictive MS definition for the risk of

Table 5: Agreement of WHO, modified ATP III and IDF criteria in identifying the MS among selected Chinese adults in Pudong New Area of Shanghai, China

\begin{tabular}{|c|c|c|c|c|c|c|c|c|}
\hline & \multicolumn{2}{|c|}{ WHO criteria } & \multirow[t]{2}{*}{$\mathbf{K}$} & \multirow[t]{2}{*}{$95 \% \mathrm{Cl}$} & \multicolumn{2}{|c|}{ ATP III criteria } & \multirow[t]{2}{*}{$\mathbf{K}$} & \multirow[t]{2}{*}{$95 \% \mathrm{Cl}$} \\
\hline & + & - & & & + & - & & \\
\hline \multicolumn{9}{|l|}{ Male } \\
\hline \multicolumn{9}{|c|}{ ATP III criteria } \\
\hline+ & 434 & 276 & & & -- & -- & & \\
\hline- & 73 & 1670 & 0.617 & $0.611-0.622$ & -- & -- & -- & \\
\hline \multicolumn{9}{|c|}{ IDF criteria } \\
\hline+ & 220 & 177 & & & 397 & 0 & & \\
\hline- & 287 & 1769 & 0.382 & $0.377-0.387$ & 313 & 1743 & 0.647 & $0.643-0.652$ \\
\hline \multicolumn{9}{|l|}{ Female } \\
\hline \multicolumn{9}{|c|}{ ATP III criteria } \\
\hline+ & 553 & 532 & & & -- & -- & & \\
\hline- & 27 & 1962 & 0.552 & $0.547-0.558$ & -- & -- & -- & \\
\hline \multicolumn{9}{|c|}{ IDF criteria } \\
\hline+ & 413 & 414 & & & 827 & 0 & & \\
\hline- & 167 & 2080 & 0.469 & $0.464-0.474$ & 258 & 1989 & 0.806 & $0.802-0.810$ \\
\hline
\end{tabular}

$\mathrm{P}<0.01$ for all $\mathrm{K}$ statistics. 


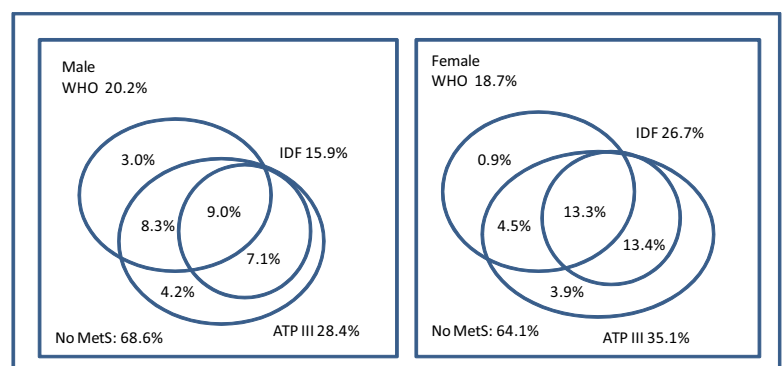

Figure 2 Overall prevalence of the MS among selected Chinese adults in Pudong New Area of Shanghai, China, according to WHO, modified ATP III and IDF criteria.

diabetes, CVD and premature death among Chinese adults. Moreover, the prevalence of the MS by WHO criteria might be underestimated in this study because impaired fasting glucose was used as the surrogate of impaired glucose tolerance which is more common in Chinese adults [32]. Finally, we cannot exclude problems associated with selection bias from the study, although our response rate to the study was quite high (89.4\%). The strengths of this study include the representative sample population, large sample size, and our rigorously standardized methods for measuring the MS components.

\section{Conclusion}

In summary, this cross-sectional study shows that the MS characterized with dyslipidemia is highly prevalent in adult population in Pudong New Area of Shanghai, China. The ongoing nutrition transition in this area and the aging of the population may have caused and will aggravate this problem in future years. Given the relatively high prevalence estimates regardless of the definition used, there is a need for a unified definition of the MS in Chinese adults that may guide prevention and treatment efforts to fight against the growing MS epidemic in China.

\section{Abbreviations}

MS: metabolic syndrome; WHO: World Health Organization; NCEP-ATP III: National Cholesterol Education Program Adult Treatment Panel; IDF: International Diabetes Federation; CVD: cardiovascular diseases; BP: Blood pressure; WC: waist circumference; BMI: Body mass index; WHR: waist-to-hip circumference ratio; FPG: fasting plasma glucose; TG: triglycerides; HDL-C: high-density lipoprotein cholesterol; LDL-C: low-density lipoprotein cholesterol; TC: total cholesterol; ACR: albumin to creatinine ratio.

\section{Competing interests}

The authors declare that they have no competing interests.

\section{Authors' contributions}

WHX contributed to the analysis and interpretation of the data and drafting of the manuscript. XNR, QLZ, HZ, YZ and $\mathrm{HQ}$ had contribution in collection, management and analysis of the study data. XJF, YB, HYW, QS and LMY contributed to the organization of the field work and collection of the study data. GMZ, JJG and QWJ contributed to the study concept and design, collection of the study data and critical revision of the article. All authors read and approved the final version of the manuscript.

\section{Acknowledgements}

This work was funded by Shanghai Municipal Health Bureau (08GWZX0201) to Dr. GM Zhao and by the Science and Technology Development Fund in Pudong New Area of Shanghai (PKJ2006-Y17) to Dr. JJ Gu. We would like to thank Dr. Charles E Matthews for his contributions to the manuscript editing. This study would not have been possible without the participation of the subjects and the support of the research staff from 17 Community Health Centers in Pudong New Area of Shanghai, China.

\section{Author Details}

1Department of Epidemiology, School of Public Health, Fudan University; Key Laboratory of Public Health Safety, Ministry of Education (Fudan University), 138 Yi Xue Yuan Road, Shanghai 200032, China, 2Pudong New Area Centers for Disease Control and Prevention, 3039 Zhang Yang Road, Shanghai 200136, China and ${ }^{3}$ Health Bureau of Shanghai Pudong New Area, 820 Cheng Shan Road, Shanghai 200125, China

Received: 25 January 2010 Accepted: 12 May 2010

Published: 12 May 2010

\section{References}

1. Sone H, Tanaka S, limuro S, Oida K, Yamasaki Y, Oikawa S, Ishibashi S, Katayama S, Ito H, Ohashi Y, Akanuma Y, Yamada N: Components of metabolic syndrome and their combinations as predictors of cardiovascular disease in Japanese patients with type 2 diabetes. Implications for improved definition. Analysis from Japan Diabetes Complications Study (JDCS). J Atheroscler Thromb 2009, 16:380-7.

2. Church TS, Thompson AM, Katzmarzyk PT, Sui X, Johannsen N, Earnest CP, Blair SN: Metabolic syndrome and diabetes, alone and in combination, as predictors of cardiovascular disease mortality among men. Diabetes Care 2009, 32:1289-94.

3. McNeill AM, Katz R, Girman CJ, Rosamond WD, Wagenknecht LE, Barzilay $\mathrm{JI}$, Tracy RP, Savage PJ, Jackson SA: Metabolic syndrome and cardiovascular disease in older people: The cardiovascular health study. J Am Geriatr Soc 2006, 54:1317-24

4. Wilson PW, D'Agostino RB, Parise H, Sullivan L, Meigs JB: Metabolic syndrome as a precursor of cardiovascular disease and type 2 diabetes mellitus. Circulation 2005, 112:3066-72.

5. Ford Es, Giles WH, Dietz WH: Prevalence of the metabolic syndrome among US adults: findings from the third National Health and Nutrition Examination Survey. JAMA 2002, 287:356-9.

6. Unwin N, Bhopal R, Hayes L, White M, Patel S, Ragoobirsingh D, Alberti G A comparison of the new international diabetes federation definition of metabolic syndrome to WHO and NCEP definitions in Chinese, European and South Asian origin adults. Ethn Dis 2007, 17:522-8.

7. Qiao Q, DECODE Study Group: Comparison of different definitions of the metabolic syndrome in relation to cardiovascular mortality in European men and women. Diabetologia 2006, 49:2837-46.

8. Gelaye B, Tafur LR, Lopez T, Sanchez S, Williams MA: Prevalence of metabolic syndrome and its relationship with leisure time physical activity among Peruvian adults. Eur J Clin Invest 2009, 39:891-8.

9. Prabhakaran D, Chaturvedi V, Shah P, Manhapra A, Jeemon P, Shah B, Reddy KS: Differences in the prevalence of metabolic syndrome in urban and rural India: a problem of urbanization. Chronic IIIn 2007, 3:8-19.

10. Gu D, Reynolds K, Wu X, Chen J, Duan X, Reynolds RF, Whelton PK, He J, InterASIA Collaborative Group: Prevalence of the metabolic syndrome and overweight among adults in China. Lancet 2005, 365:1398-405.

11. Zuo H, Shi Z, Hu X, Wu M, Guo Z, Hussain A: Prevalence of metabolic syndrome and factors associated with its components in Chinese adults. Metabolism 2009, 58:1102-8

12. Zhang WW, Liu CY, Wang YJ, Xu ZQ, Chen Y, Zhou HD: Metabolic syndrome increases the risk of stroke: a 5-year follow-up study in a Chinese population. J Neurol 2009, 256:1493-9.

13. Villegas $R$, Xiang YB, Yang G, Cai Q, Fazio S, Linton MF, Elasy T, Xu WH, Li H, Cai H, Gao YT, Zheng W, Shu XO: Prevalence and Determinants of Metabolic Syndrome According to Three Definitions in Middle-Aged Chinese Men. Metab Syndr Relat Disord 2008 in press.

14. Archival documents compilation committee of Pudong New Area of Shanghai. Yearbook of Pudong New Area of Shanghai 2006. Chinese 
15. Shanghai Civil Affairs Bureau: Statistical information of surveillance on aged population and ageing of population in Shanghai 2008. [http:// www.shmzi.gov.cn/gb/shmzj/node8/node15/node58/node72/node99/ userobject1ai22368.html]. Chinese

16. Alberti KG, Zimmet PZ: Definition, diagnosis and classification of diabetes mellitus and its complications. Part 1: diagnosis and classification of diabetes mellitus provisional report of a WHO consultation. Diabet Med 1998, 15:539-53.

17. Denke MA, Pasternak RC: Defining and treating the metabolic syndrome: a primer from the Adult Treatment Panel III. Curr Treat Options Cardiovasc Med 2001, 3:251-3.

18. Alberti KG, Zimmet P, Shaw J, IDF Epidemiology Task Force Consensus Group: The metabolic syndrome--a new worldwide definition. Lancet 2005, 366:1059-62.

19. Shanghai Statistics Bureau: Statistical data of population census 2000 in Shanghai. [http://www.stats-sh.gov.cn/2004shtj/wpzc/tables/1 8.htm]. Chinese

20. Cooperation group: Further study of risk factors for stroke and coronary heart disease. The prevalence of metabolic syndrome in 11 provinces cohort in China. Chin J Prev Med 2002, 26:298-300. Chinese

21. Yang W, Reynolds K, Gu D, Chen J, He J: A comparison of two proposed definitions for metabolic syndrome in the Chinese adult population. Am J Med Sci 2007, 334:184-9.

22. Bener A, Zirie M, Musallam M, Khader YS, Al-Hamaq AO: Prevalence of metabolic syndrome according to Adult Treatment Panel III and International Diabetes Federation criteria: a population-based study. Metab Syndr Relat Disord 2009, 7:221-9.

23. National Bureau of Statistics of China: Shanghai Statistical Yearbook; 2009.

24. Kuzuya M, Ando F, Iguchi A, Shimokata H: Age-specific change of prevalence of metabolic syndrome: longitudinal observation of large Japanese cohort. Atherosclerosis 2007, 191:305-12.

25. Yuan G, Al-Shali KZ, Hegele RA: Hypertriglyceridemia: its etiology, effects and treatment. CMAJ 2007, 176:1113-20.

26. Roberts CK, Barnard RJ: Effects of exercise and diet on chronic disease. $J$ Appl Physio 2005, 98:3-30.

27. Sumner AE: Ethnic differences in triglyceride levels and high-density lipoprotein lead to underdiagnosis of the metabolic syndrome in black children and adults. J Pediatr 2009, 155:S7.e7-11.

28. DECODA Study Group: Prevalence of the metabolic syndrome in populations of Asian origin. Comparison of the IDF definition with the NCEP definition. Diabetes Res Clin Pract 2007, 76:57-67.

29. Athyros VG, Ganotakis ES, Elisaf MS, Liberopoulos EN, Goudevenos IA, Karagiannis A, GREECE-MS Collaborative Group: Prevalence of vascular disease in metabolic syndrome using three proposed definitions. Int $\mathrm{J}$ Cardio/ 2007, 117:204-10.

30. Sung KC, Kim BJ, Kim BS, Lee WY, Park JB, Wilson AM: A comparison of the prevalence of the MS and its complications using three proposed definitions in Korean subjects. Am J Cardiol 2009, 103:1732-5.

31. Meigs JB: Invited commentary: insulin resistance syndrome? Syndrome $X$ ? Multiple metabolic syndrome? A syndrome at all? Factor analysis reveals patterns in the fabric of correlated metabolic risk factors. Am J Epidemiol 2000, 152:908-11.

32. Lü Q, Tong N, Liu Y, Li N, Tang X, Zhao J, Cao H, Li D, Gou L, Zhang Y, Wan J, Jiang L: Community-based population data indicates the significant alterations of insulin resistance, chronic inflammation and urine ACR in IFG combined IGT group among prediabetic population. Diabetes Res Clin Pract 2009, 84:319-24.

\section{Pre-publication history}

The pre-publication history for this paper can be accessed here: http://www.biomedcentral.com/1471-2458/10/246/prepub

\section{doi: 10.1186/1471-2458-10-246}

Cite this article as: Xu et al., Prevalence of the metabolic syndrome in Pudong New Area of Shanghai using three proposed definitions among Chinese adults BMC Public Health 2010, 10:246

\section{Submit your next manuscript to BioMed Central} and take full advantage of:

- Convenient online submission

- Thorough peer review

- No space constraints or color figure charges

- Immediate publication on acceptance

- Inclusion in PubMed, CAS, Scopus and Google Scholar

- Research which is freely available for redistribution

Submit your manuscript at www.biomedcentral.com/submit
C BioMed Central 